\title{
Chapter 31 \\ HURRICANE STORM SURGE CONSIDERED AS \\ A RESONANCE PHENOMENON
}

\author{
by \\ G. Abraham* \\ Waterloopkundig Laboratorium \\ Delft, Netherlands
}

\begin{abstract}
A model study was performed to study the water gravity waves generated by a circular local disturbance of pressure, advancing with constant velocity over the surface of water of constant depth. The results indicate that under critical conditions a resonance type phenomenon occurs for which the associated wave heights have a maximum value. It is shown that the resonant conditions may be an important factor for the generation of the surge due to hurricanes, that approach the coast perpendicularly.
\end{abstract}

\section{INTRODUCTION}

Presented in the first part of this paper is a summary of the results of a model investigation of the water waves generated by a local disturbance, consisting of a circular pressure area, advancing with constant velocity over the surface of water with constant depth. A more detailed description of this model study is given elsewhere (Abraham, 1960). The results indicate that under critical conditions a resonance type phenomenon occurs for which the associated wave heights have a maximum value, a result similar to that of a two dimensional model investigation performed by Wiegel et al (1958).

A hurricane is an example of a moving circular pressure area in nature. Unfortunately the ratio of the diameter of the disturbance to the water depth is for a hurricane much larger than could be obtained in the model. Hence it will be difficult to draw quantitative conclusions from the model results. Nevertheless it is possible to show as is done in the second part of this paper - that the resonant conditions may be an important factor for the generation of the surge due to hurricanes, that approach the coast perpendicularly.

*The work described herein was performed while the author was a Fulbright Research Scholar at the University of California 


\section{COASTAL ENGINEERING}

\section{PART 1: SUMMARY OF MODEL RESULTS}

\section{a. MODEL SET-UP AND EXPERIMENTAL PROCEDURE}

A moving low pressure area was simulated in the model by towing a suction fan over the water surface. No attempt has been made to simulate a certain wind pattern in the pressure disturbance. The plane of the edge of the inlet pipe was about $1-1 / 2$ inche above the undisturbed water level. Three different sizes of the inlet pipes were used. Their diameters were 2,1 and $1 / 2$ feet.

The experiments were performed in the wave-towing tank of the University of California which had a length of 200 feet and a width of 8 feet (Snyder, et al, 1958). The water depth was $1 / 2$ foot for the experiments that showed the resonance-type phenomenon.

The towing carriage could be operated at any speed up to a maximum of about $6 \mathrm{ft} / \mathrm{sec}$.

The time history of the water surface of the waves generated by the advancing pressure disturbance were measured in one cross $\mathbf{s e c}-$ tion of the tank. Five parallel wire resistance wave recorders were used.

At the beginning of an experiment the automatic carriage control unit was set for a chosen carriage speed. The fan then was started. As soon as the static water displacement had reached equilibrium the towing carriage was set in motion.

The wave recorders were switched on just prior to the moment at which the low pressure area reached the recorders. They registered five longitudinal cross sections of the wave system, by which the moving pressure distur bance was accompanied.

A wave recorder was used to measure the elevation of the water surface underneath the inlet pipe with the low pressure area being held stationary. This was considered to be the same as the pressure at the undisturbed water level expressed as the length of a column of water. It varied with a frequency of about 5 c.p.s. from about $70 \%$ to $130 \%$ of its mean value, called the static water displacement $H_{S}$.

The pressure distribution underneath a moving inlet pipe was not measured because of the difficulties involved. It has been assumed that the pressure distribution would not be influenced considerably by the movement of the low pressure area, because of the following reasons. The water surface was not affected by the movement of the inlet pipe as long as the fan was not turned on. Secondly, the forward velocity of the low pressure area was small compared with the velocity of the air 


\section{HURRICANE STORM SURGE CONSIDERED AS A RESONANCE PHENOMENON}

entering the inlet pipe through the opening between the edge of the pipe and the water surface.

\section{b. MODEL RESULTS}

One of the wave recorders was located in the path of the center of the low pressure area. The wave height $H$, measured by it for the first, the second and the third wave crest of the wave system by which the pres sure disturbance was accompanied, can be seen to be a function of the velocity of the low pressure area (fig. 1). The relationship between the wave height and the speed of the disturbance was found to depend on the ratio of the diameter of the disturbance $D$ to the waterdepth $d$.

Fig. 2a shows the envelope of the lines given in fig. 1 and a corresponding theoretical curve for $\mathrm{D} / \mathrm{d}$ tending to infinity, which has been calculated by Inui (1936). The shallow water resonance peak (called the shallow water maximum) only occurred for the experiments with $\mathrm{D} / \mathrm{d}=4,2$ and 1 . The other maxima that can be seen on this figure are not important when hurricanes with large values of $D / d$ are considered. The velocity of the disturbance for which the resonant conditions occurred was in the model a little less than the velocity of the shallow water wave, $\sqrt{\mathrm{gd}}$, the theoretical value of this speed for large values of $\mathrm{D} / \mathrm{d}$ (fig. 2c).

Regarding the height of the resonance peak, that can be seen on figs. $2 a$ and $2 b$, we should remark that the wave height is influenced by scale effects for wave heights satisfying $\mathrm{H}_{\max } / \mathrm{H}_{\mathrm{S}}>4$. For this condition the air pressure at the water surface was influenced by the reduced distance between the water surface and the plane of the edge of the inlet pipe. Scale effects of this kind did not occur for $\mathrm{H}_{\max } / \mathrm{H}_{\mathrm{S}}<4$.

Fig. 3 shows the phase shift, this is the distance between the center of the disturbance and the first wave crest, for the shallowwater experiments. The decay of the wave height along a line normal to the line of advance of the pressure area can be seen on fig. 4. The waves registered for the shallow-water maxima can be seen on fig. 5 .

\section{PART 2: APPLICATION OF MODEL RESULTS TO HURRICANE WAVES}

A hurricane may be considered as a roughly circular disturbance with an area of low barometric pressure and strong counter-clockwise (in the northern hemisphere) winds, that advances with a certain velocity. The diameter of a hurricane is in general 50 to 100 nautical miles, so that the ratio $\mathrm{D} / \mathrm{d}$ is in general at least 100 when a hurricane moves over an ocean surface. 

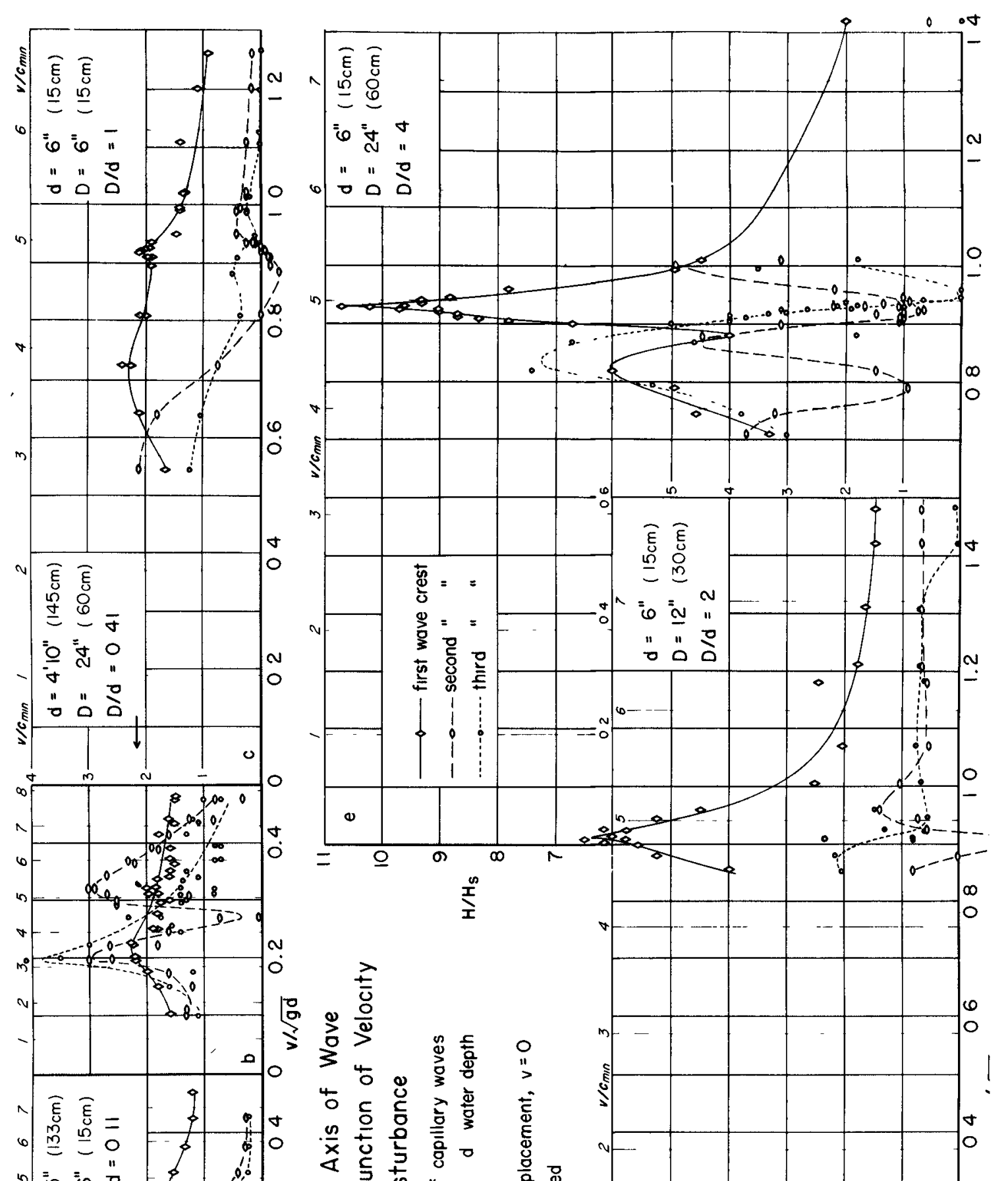

in
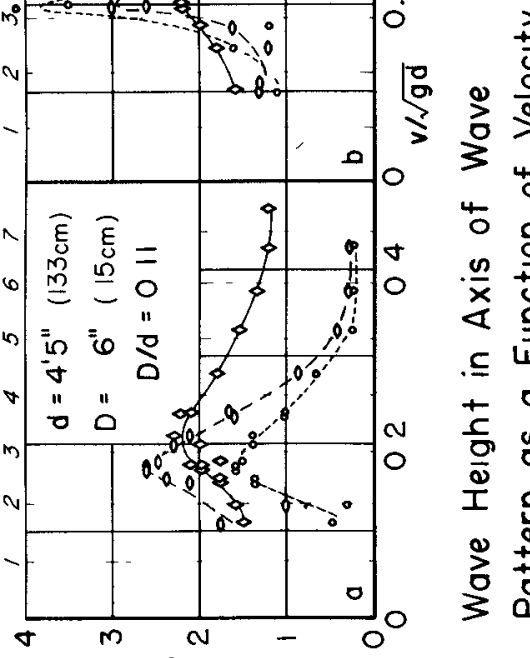

$\frac{\frac{1}{0}}{\frac{0}{2}}$

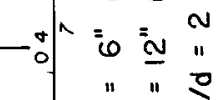




\section{HURRICANE STORM SURGE CONSIDERED AS \\ A RESONANCE PHENOMENON}

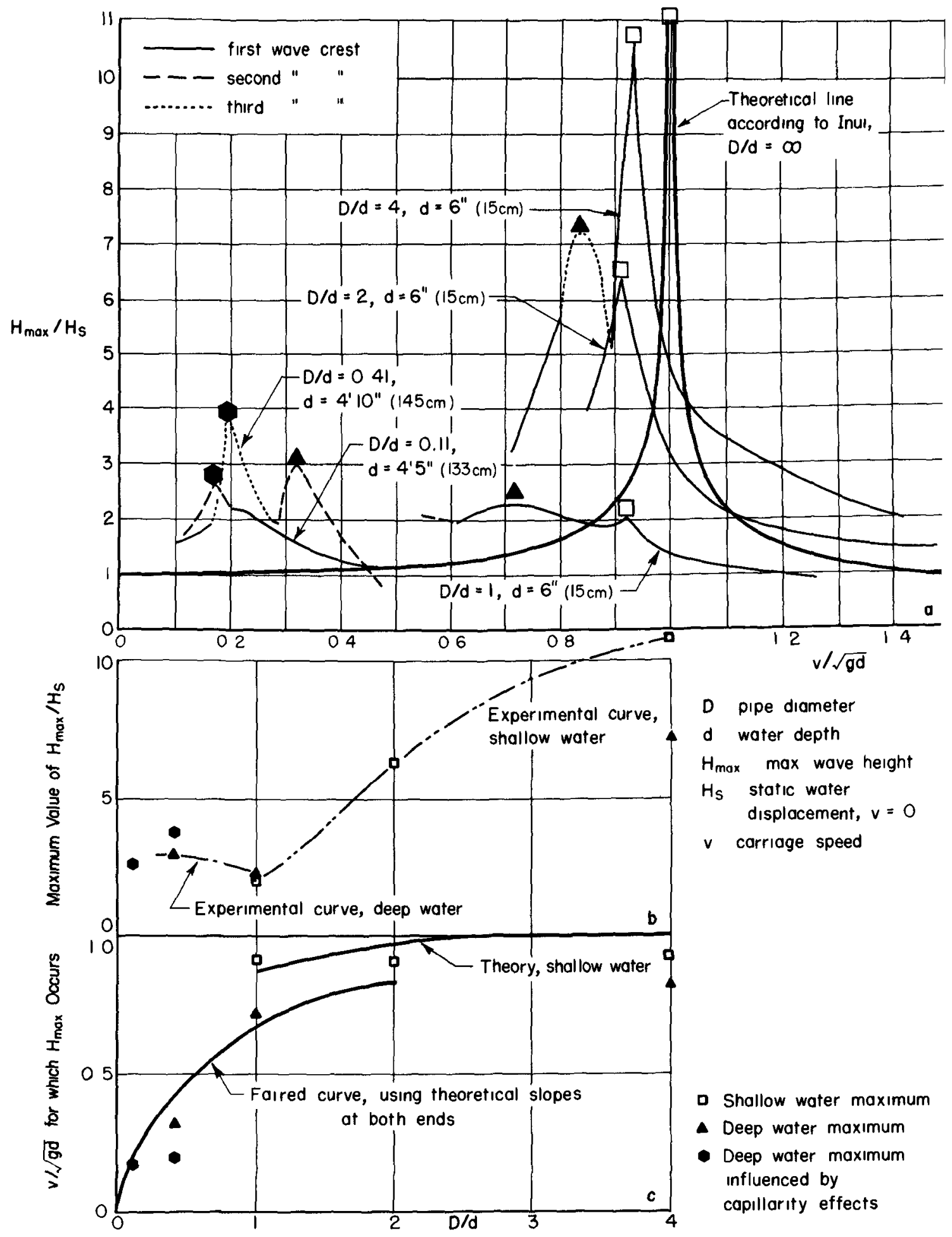

Maximum Wave Height in Axis of Wave Pattern as a Function of Velocity and Diameter of Pressure Disturbance 
COASTAL ENGINEERING

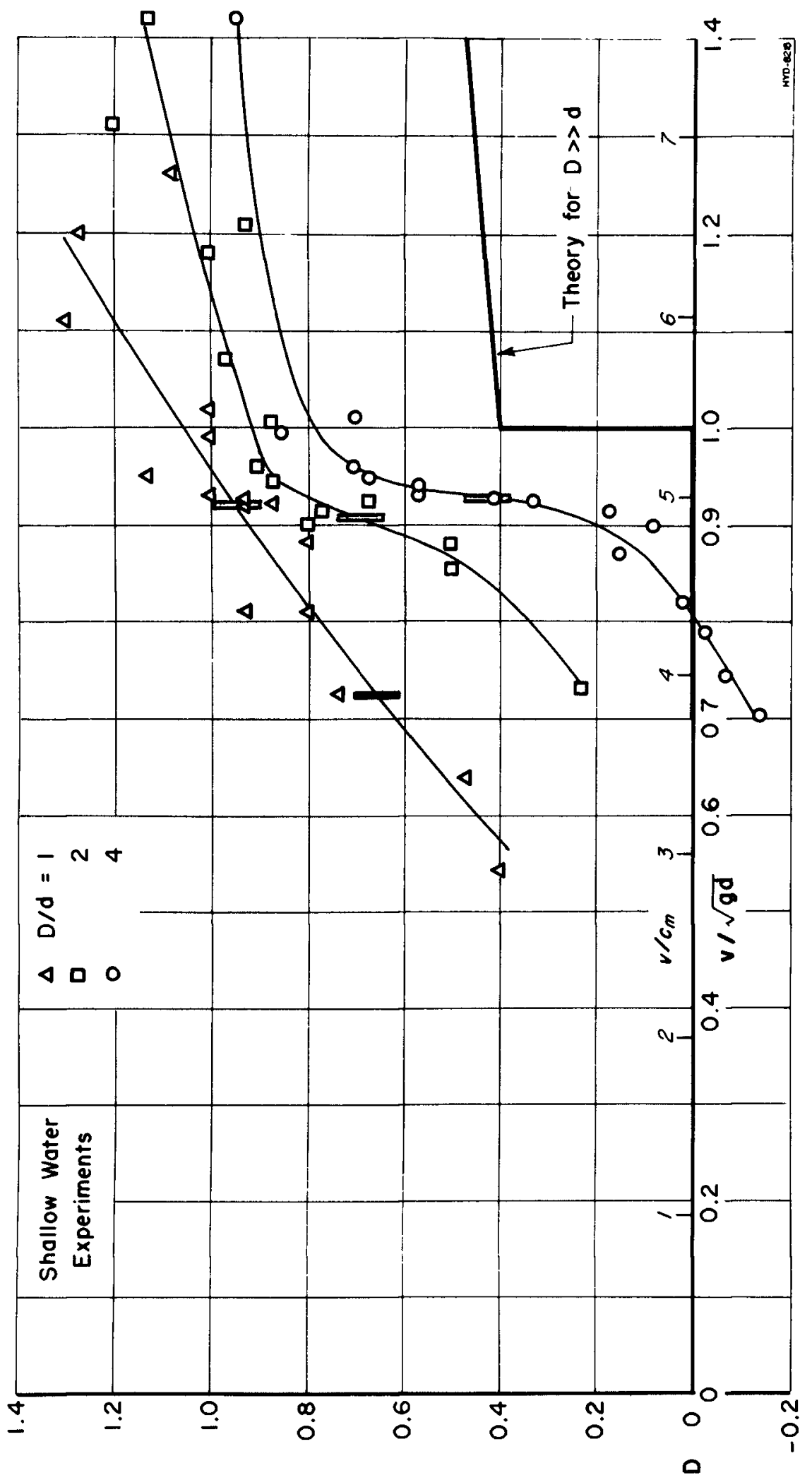

$\%$

这

i்

당.

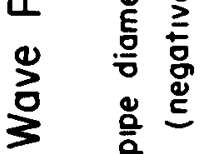

ᄂ

$\frac{n}{x}$

$\subseteq$

$\frac{5}{6}$
$\frac{1}{n}$
员
$\frac{2}{a}$

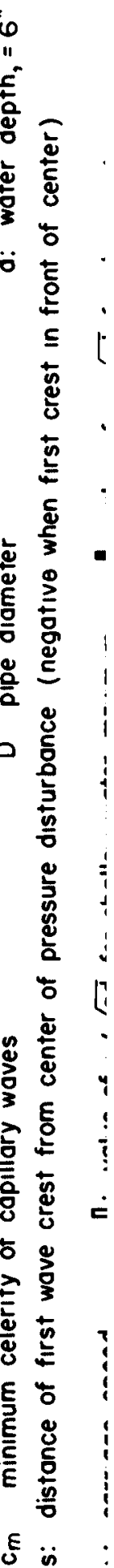


HURRICANE STORM SURGE CONSIDERED AS

A RESONANCE PHENOMENON

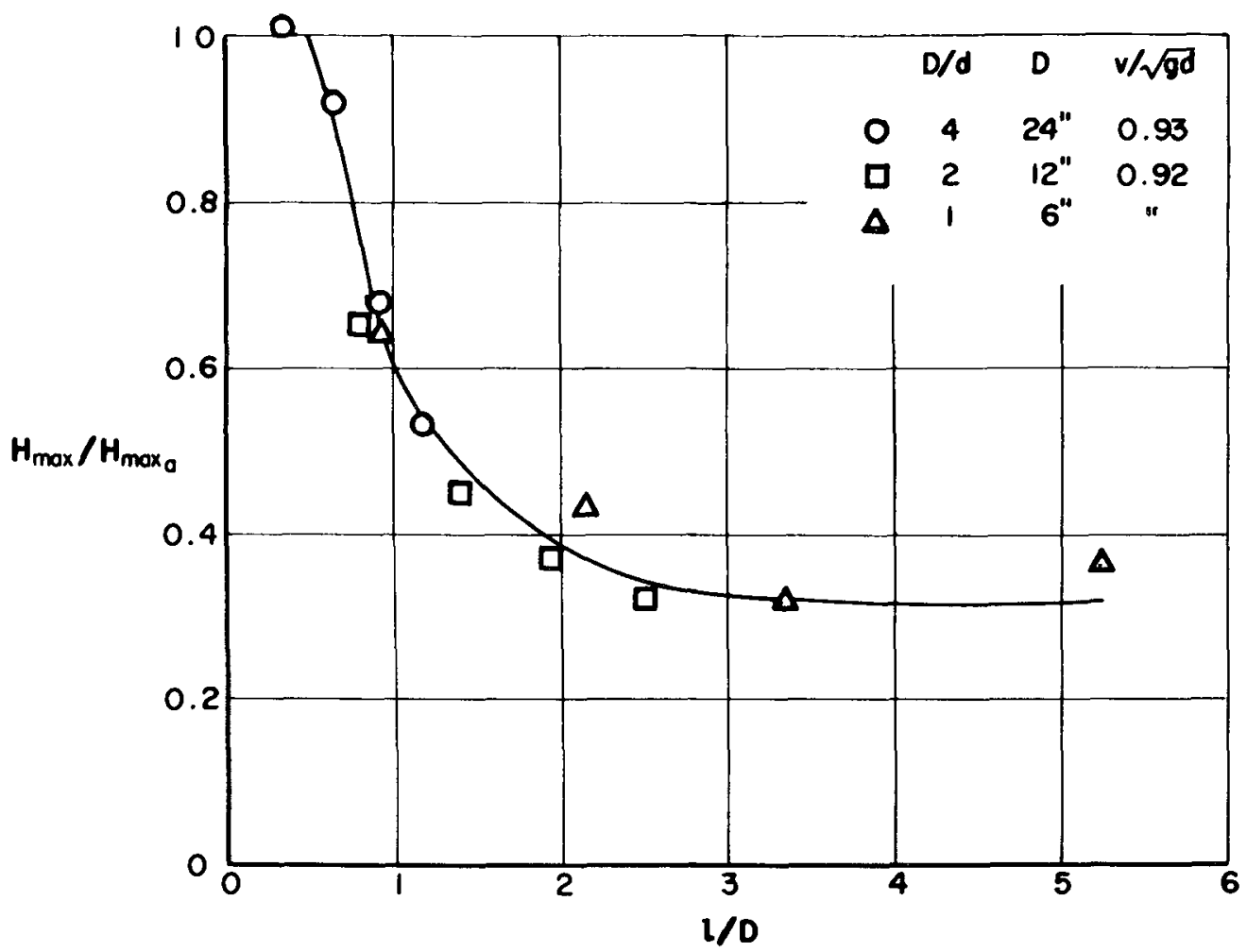

Shallow Water Maxima. Maximum wave height as a function of distance to axis of wave pattern.

D: diameter of pipe

d. woter depth, $=6^{\prime \prime}$

$H_{\text {max }} \cdot$ maximum wave height of distance $l$ from axis

$H_{\text {max }}$ : maximum wove height in axis of wave pattern

$v$ : corriage speed

FIGURE 4 


\section{COASTAL ENGINEERING}
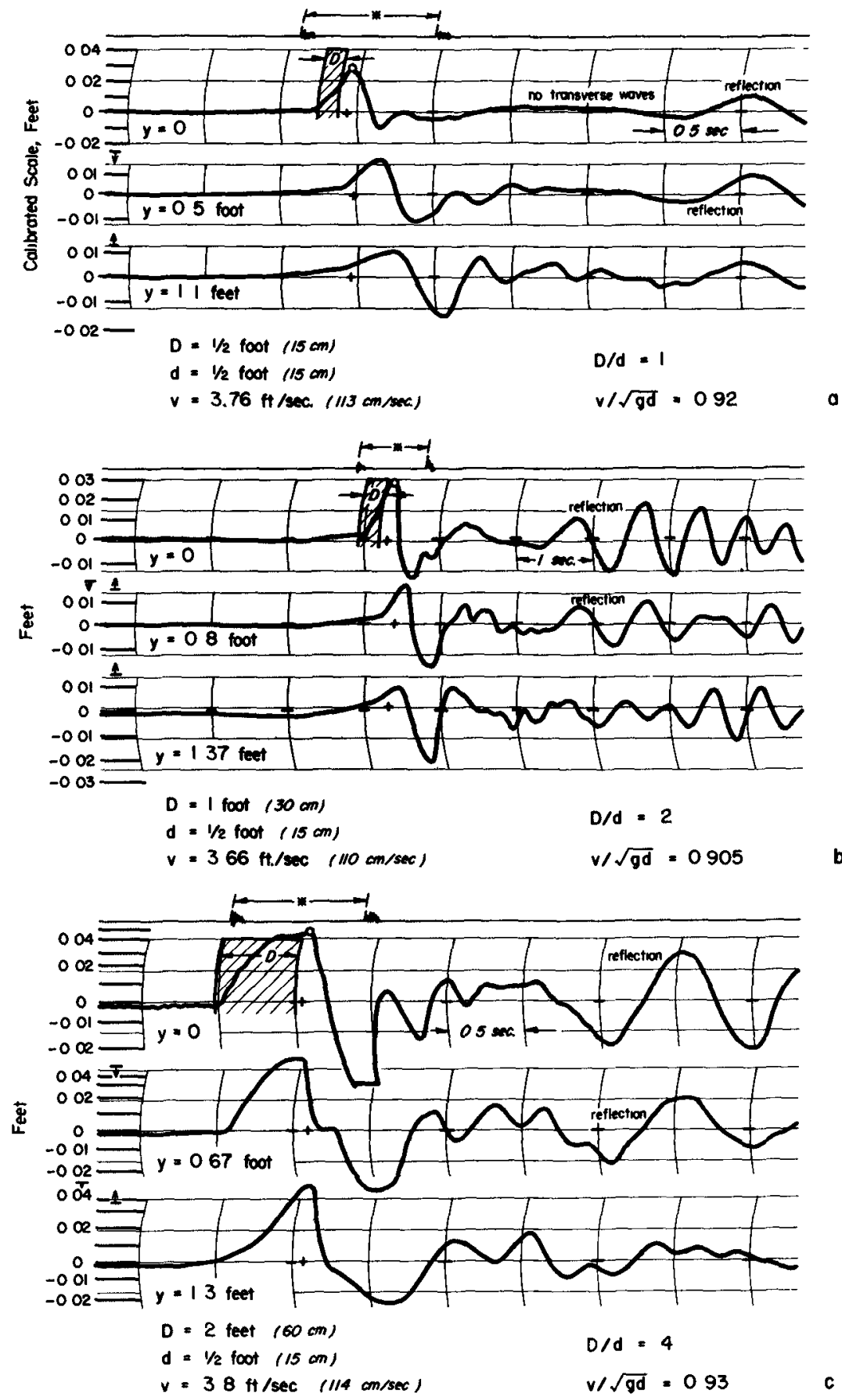

D. pipe diometer

d water depth

$v$ carr lage speed

$y$ distonce to axis of wave pattern
+ moment at which center of wove pattern (0) posses probes

* length scale corresponds to 333 feet in wave pattern

VIT position of low press area as it passes probes

Shallow Water Maximum 


\section{HURRICANE STORM SURGE CONSIDERED AS A RESONANCE PHENOMENON}

When this happens three phenomena occur. Wind waves are generated because of the winds, water is dragged along the surface by the winds causing a wind set-up along the coast, and the actual level of a portion of the sea surface becomes higher because of the low barometric pressure. The latter two increments of the water level, taken together, is called the storm surge. At the coast it is taken to be the difference between the normal tide as predicted in the tide tables and the actual recorded storm tide.

Records obtained during hurricanes (Redfield and Miller, 1955) show that the magnitude of the storm surge in the open deep sea is close to the static water displacement. It seems that shallow water (for instance above the continental shelf) is required for the development of storm surges greatly in excess of the static water displacement.

At a coast, where the water depth is restricted, the following phenomena occur: (1) The restricted depth will result in an increment of wind set-up. (2) It will also cause a shallow-water maximum when the advancing velocity of the hurricane satisfies the required conditions and when there is sufficient time available to build up these maxima. (3) Once they are generated, the shallow-water maxima, which are long waves of very small steepness, will run up, be reflected from, or otherwise be influenced by the coast. The result of these three phenomena are the high storm surges along the coast, where the path of the hurricane crosses the coast line. It is difficult to determine the exact contribution of each of these phenomena to an actual recorded surge.

In the following, we will try to make an estimation of the contribution of the shallow-water maxima. At first we will present, however, three prototype examples, which show resonant shallow-water conditions that have been recorded in nature.

$1^{\circ}$ THE LAKE MICHIGAN WAVE OF JUNE 26th, 1954 (Ewing et al, 1954).

"On the morning of June 26th, 1954 about 9:30 A.M. an abrupt increase in the level of Lake Michigan occurred along the waterfront in the vicinity of Chicago. According to observations, the wave approached Chicago from the east to southeast. It was first observed at Michigan City at $8: 10$. Here the wave approached from the nor thwest. Fig. 6 gives the local situation, table 1 gives lake-height da'a.

A few hours earlier a severe squall line with winds up to $61 \mathrm{~m} \cdot \mathrm{p} . \mathrm{h}$. had arrived from the northwest and crossed southern Lake Michigan. Its maximum lateral extent was about $150 \mathrm{mi}$. Associated with the 


\section{COASTAL ENGINEERING}

Table 1. Wave height and arrival time

\begin{tabular}{lcc} 
Station & Arrival \\
Reported height $(\mathrm{ft})$ & time \\
& (A.M. CTD) \\
\hline
\end{tabular}

EASTERN SIDE OF LAKE

St. Joseph

Michigan City

USCGS

Breakwater

WESTERN SIDE OF LAKE

Chicago

Belmont Harbor

Montrose Harbor

North Ave.

River mouth

Waukegan
No significant change

$$
6.2
$$

$8: 12$

5.5

$8: 10$

$\begin{array}{rl}6.3 & 9: 30 \\ 8.0 & 9: 25 \\ 10.0 & 9: 30 \\ 2.4 & 9: 40\end{array}$

No significant change 

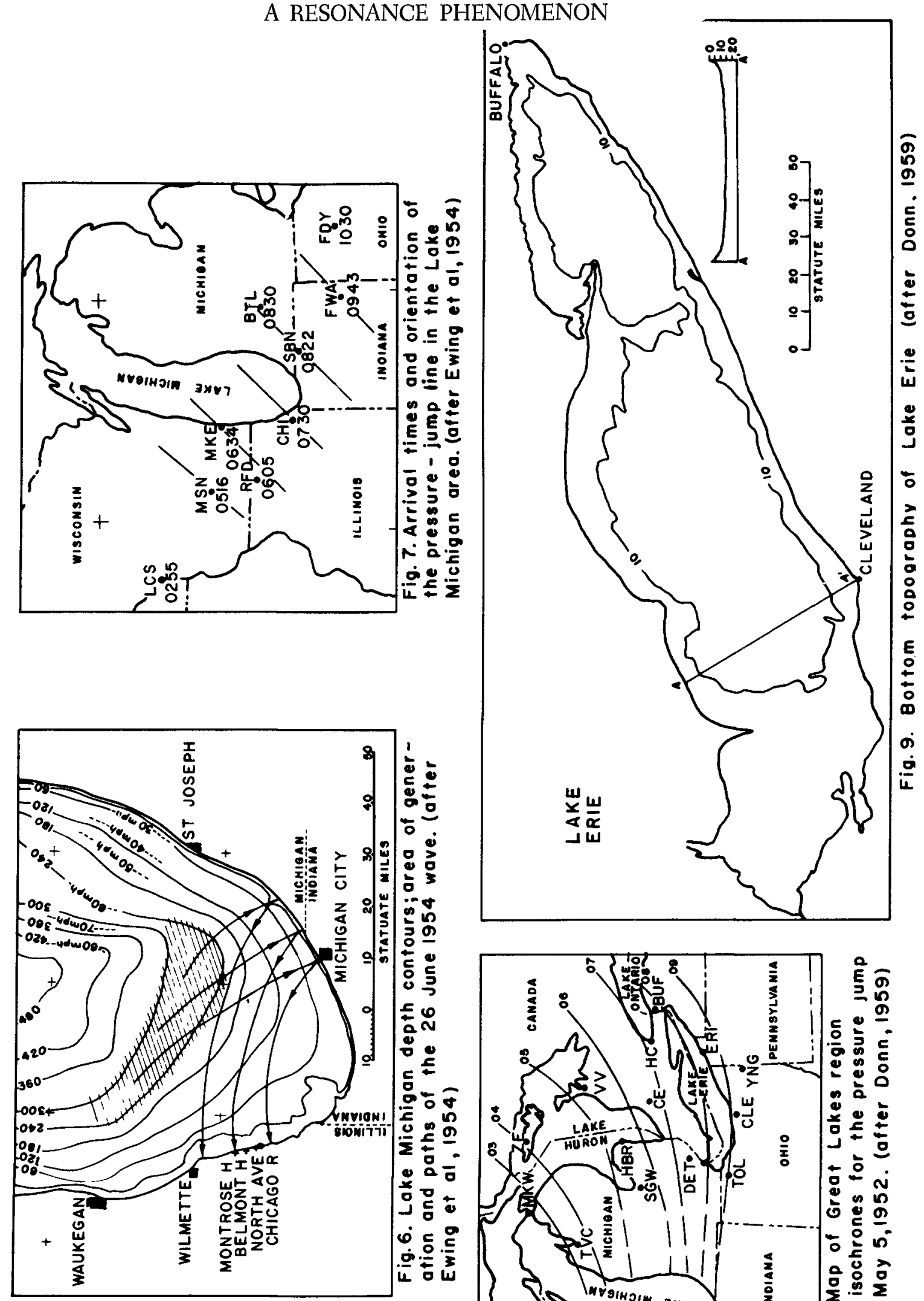
squall line was a very rapid and strong pressure jump which for most stz tions for which records are available amounted to about 0.1 in. in a few minutes. The progress of the pressure jump line is shown in fig. 7 . It crossed Lake Michigan with a velocity of $66 \mathrm{~m} . \mathrm{p} . \mathrm{h}$. It arrived at Michigan City simultaneously with the wave from the northwest.

The critical depth for which the long wave velocity $(\sqrt{\mathrm{gd}})$ is equal to the speed of the disturbance of $66 \mathrm{~m} . \mathrm{p} . \mathrm{h}$. is $288 \mathrm{ft}$. Such a depth exists for a relatively long fetch almost exactly in the direction of squall movement between 240 and $300 \mathrm{ft}$. depth contours (fig. 6). Hence it is evident that a resonant shallow-water maximum could be generated. The approximate area of generation is indicated by cross hatching. Since the wave was moving in an area of variable depth, refraction effect induced a deflection of the wave path towards shallower water, producing paths approximately like those shown by the heavy arrows, which indicate the incidence of the wave at the east coast and its reflection at the west coast. The times of occurrence of the various events are compatible with this explanation".

The significance of this example is that it shows a reflected long wave, which supports that the surge has been explained as a resonant shallow-water maximum. This example makes it possible to determine the time which was available to build up the shallow-water maximum by dividing the length of the area of generation by the speed of the line of squall. The time, determined by this manner, is about $40 \mathrm{~min}$.

$2^{\circ}$ THE LAKE ERIE STORM SURGE OF MAY 5th, 1952 (Donn, 1959).

"On the morning of May 5,'1952 a strong pressure disturbance crossed Lake Erie, with an average speed of $32 \mathrm{~m} \cdot \mathrm{p} . \mathrm{h}$. The disturbanc line moved parallel to the long axis of the lake (fig. 8). The magnitude of the pressure jump was about 0.08 inches, when it passed Cleveland. On arrival of the pressure jump the wind shifted there from northeast to southeast at 20 to $30 \mathrm{~m} . \mathrm{p} . \mathrm{h}$. Simultaneously with the pressure jump a wave of $1.7 \mathrm{ft}$. has been recorded at Cleveland.

It is evident from the map and profile in fig. 9 that the bottom of Lake Erie is quite flat. Based on the depth along profile $\mathrm{AA}^{\prime}$, the velocity of a long gravity wave here is about $30 \mathrm{~m} . \mathrm{p} . \mathrm{h}$., making it quite reasonable that resonant transfer of energy occurred between the air and a long gravity wave generated in the lake."

The first wave crest was followed by a set of high amplitude waves which according to Donn either can be explained as repeated reflections (through he indicates that lack of any attenuation for the first waves tenc to weaken the argument for the repeated reflections) or as a seiche set $\mathrm{l}$ by the initial water transfer to the southern end of the lake. 


\section{HURRICANE STORM SURGE CONSIDERED AS A RESONANCE PHENOMENON}

The time available for the generation of the shallow-water maximum of this example was about 80 minutes. This time has been calculated assuming the length of the generation area to be the distance between the 10 fathom contours in profile $\mathrm{AA}^{\prime}$ (fig. 9).

\section{$3^{\circ}$ HURRICANE CAROL, AUGUST 30th - 31st, 1954 (Harris, 1956)}

Fig. 10 is a reproduction in reduced size of a section of U.S.C. \& G.S. Chart No. 1000 (Cape Sable to Cape Hatteras) showing water depths of the East Coast of the United States. The path of the center of Hurricane Carol is plotted on this chart (Harris, 1956).

Fig. 11 shows the storm surges as recorded for several stations along the coast during Hurricane Carol . Hurricane Carol travelled for an appreciable distance with a forward speed of approximately 30 to 35 knots (between Cape Hatteras and Long Island). The shallow-water wave velocities $\sqrt{\text { gd }}$ associated with water depths of $5 ; 10 ; 15 ; 20$ and 25 fathoms are $18.5 ; 26.1 ; 31.9 ; 36.8$ and $41.2 \mathrm{kn}$. So it is evident that if Hurricane Carol could have been able to generate a shallow-water maximum, this should have been in the vicinity of Long Island. The significance of this example is that it. shows that the time histories of the stations near Long Island are in agreement with the time history of the model shallow-water maxima of fig. 5. For all the stations near Long Island the prototype-time histories have the phase shift and the relatively large trough in the rear of the resonance peak in common with the model time histories of fig. 5. In both prototype and model the time during which the resonance peak occurs is about equal to the diameter of the low pressure area divided by its advancing velocity. For the model the latter fact follows from fig. 5 and for the prototype it has been shown by Redfield and Miller (1957).

The examples show the following: (1) An available period of time of about 40 to 80 minutes was sufficient for the development of resonant shallow-water maxima for the two dimensional first and second examples (line disturbances), (2) According to the three dimensional third example there are prototype data that qualitatively agree well with the three dimensional model data.

To obtain the relationship between the velocity of the disturbance and the height of the generated waves for hurricanes, we have to extrapolate the model results obtained for $1<D / d<4$ to $D / d>100$.

The theoretical curve for the resonance according to Inui in fig. $2 \mathrm{a}$ seems to be the most adequate tool for the extrapolation of the model results, although it was derived using linear wave theory, which neglects friction and assumes negligible wave heights. Havelock (1922) showed, however, that according to linear wave theory the shallow-water 
COASTAL ENGINEERING

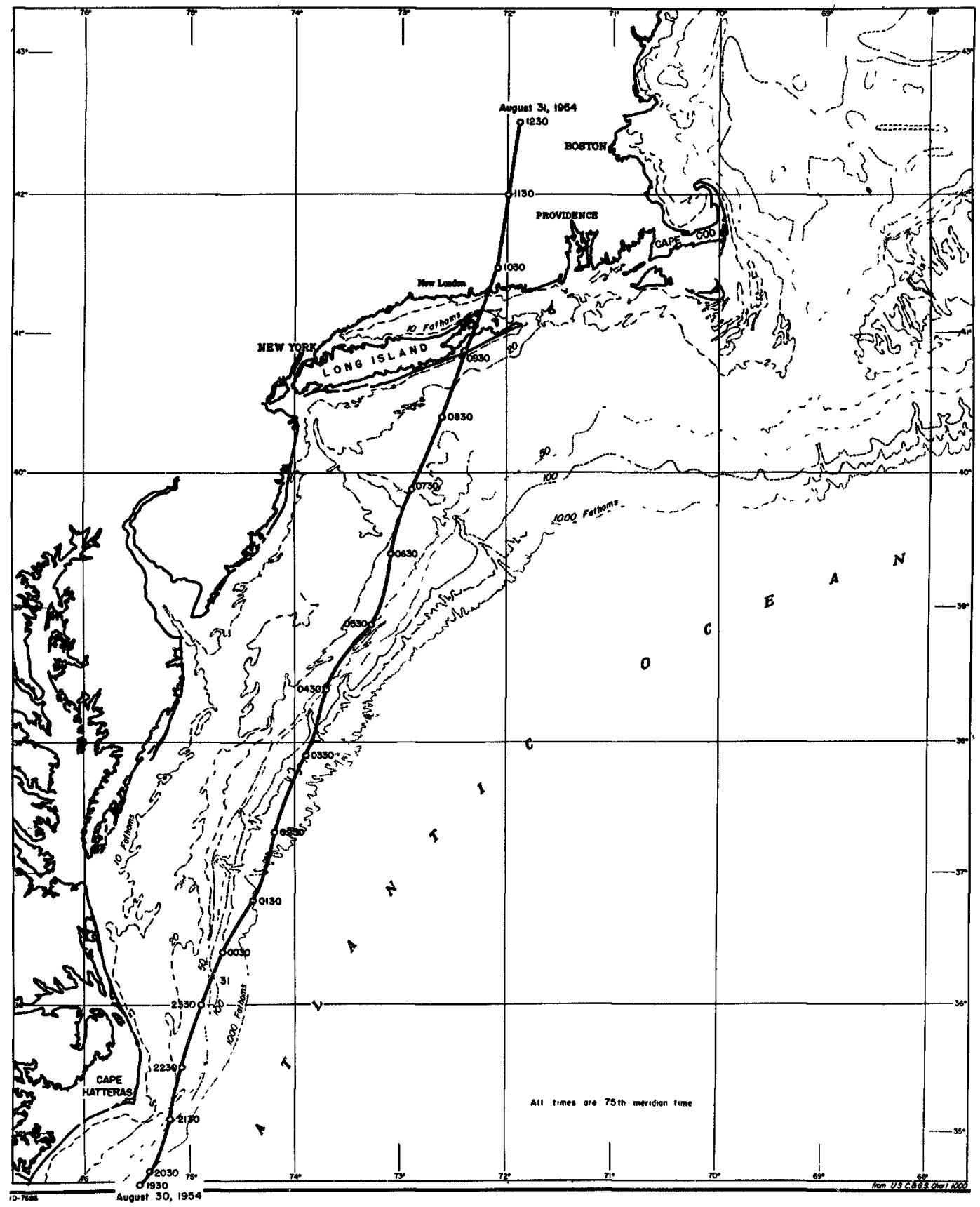

Path of center of hurricane CAROL, 30-31 August 1954 (after Harris, 1956) $\quad 598$ 

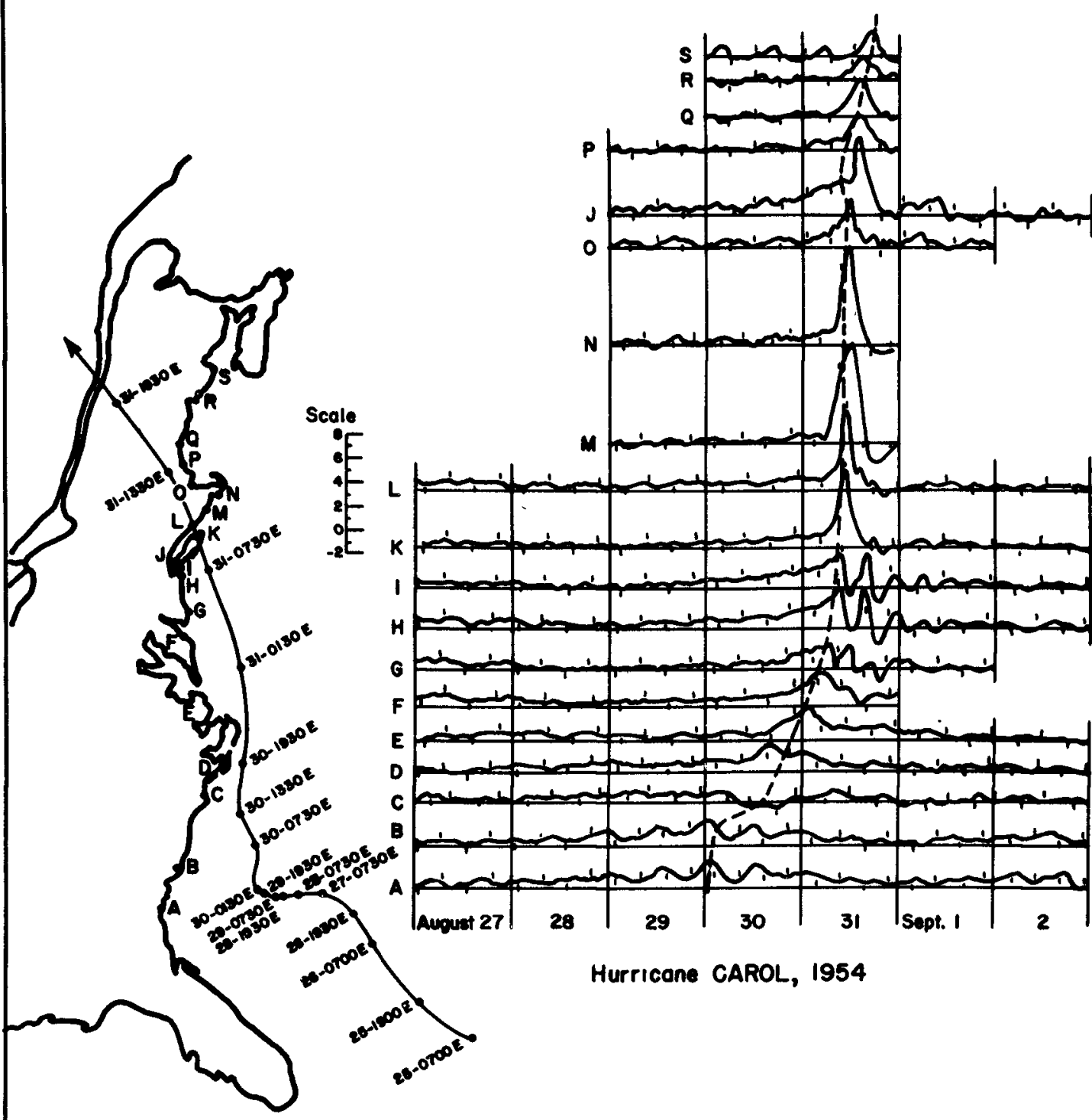

Hurricane CAROL, 1954

\section{STATIONS :}

A. Fort Puloski, Ga.

Q. Charleston, S. C.

C. Wilmington, N. C.

D. Moreheod City, N. C.

E. Hompton Roads, Va.

F. Breakwater Harbor, Del.

G. Attantic City, N. J.

H. Sondy Hook, N. J.

I. The Battery, New York City, N. Y.

J. Willets Point, N. Y.

K. Montouk Point, N. Y.

L. New London, Com.

M. Newport, R. I.

N. Woods Hole, Mass.

O. Boston, Mass.

P. Portemouth, N. H.

Q. Portland, Me.

R. Bor Horbor, Me.

S. Eastport, Me.

Houriy storm surge height (observed minus predicted sea level), Atlontic coast tide stations, August 27 - September 2, 1954. ( ofter Harris, 1956) 
maxima become higher when the ratio $\mathrm{D} / \mathrm{d}$ increases. The physical rea soning that a water particle in the path of the center of the pressure area is subjected to a vertical farce during a longer period of time, when the diameter of the disturbance is larger, while its speed remains the same, yields the same result. Hence we may assume that shallow water maxima of at least the same relative height, compared with the static water displacement as those observed in the model, may occur in nature, as long as the ratio $\mathrm{H}_{\mathrm{S}} / \mathrm{d}$ is the same for model and prototype. For our experiments the magnitude of this ratio varied between 0.01 and 0.02 .

According to the foregoing the theoretical curve combined with the model results shows that shallow-water maxima up to 2 times the static water displacement may be considered to be possible for hurricanes that advance during a sufficiently long period of time over water having a depth $d$, satisfying $0.75 d_{c r}<d<1.25 d_{c r}$, where $\dot{v}=\sqrt{g^{d} d_{c r}}$. Maxima up to 3 times the static water displacem ent may be considered to be possible for hurricanes that advance during a sufficiently long period over water having a depth satisfying $0.9 \mathrm{~d}_{\mathrm{cr}}<\mathrm{d}<1.1 \mathrm{~d} c \mathrm{c}$.

It is impossible to make an estimation of the required period of time by extrapolating the model data because of the difference of the ratio $D / d$. The theoretical curve shows, however, the following. The wave height varies gradually with decreasing depth for $0<\mathrm{V} / \sqrt{\mathrm{gd}}<0.8$ or for $1<\mathrm{Hmax} / \mathrm{H}_{\mathrm{S}}<2$. For $\mathrm{v} / \sqrt{\mathrm{gd}}>0.8$ the wave height varies more rapidly. Hence it seems safe to assume that shallow-water maxima satisfying $\mathrm{H}_{\max } / \mathrm{H}_{S}=2$ occur in nature, when a hurricane, that has advanced for a considerable length over the ocean surface, moves over a (continental) shelf, where the water depth gradually approaches the critical depth. For this case the shallow-water maxima may develop gradually from $\mathrm{H}_{\max } / \mathrm{H}_{\mathbf{S}}=1$ to $\mathrm{H}_{\max } / \mathrm{H}_{\mathbf{S}}=2$.

A similar initial period was not available for the two dimensional examples, which nevertheless showed considerable wave heights. There fore it seems reasonable that the period of time that was available for the two dimensional examples (order of magnitude one hour) may be considered to be sufficient for the development of considerable shallow water maxima (say $\mathrm{H}_{\max } / \mathrm{H}_{\mathrm{S}}=3$ ) for three dimensional disturbances with a long initial fetch, which move during this one hour period over water having the required depth $\left(0.9 \mathrm{~d}_{\mathrm{cr}}<\mathrm{d}<1.1 \mathrm{~d}_{\mathrm{cr}}\right)$.

\section{CONCLUSIONS}

We may draw the following final conclusions: (1) A period of time of the order of magnitude of one hour may be considered to be sufficient for the development of three dimens ional shallow-water maxima in nature. (2) Assuming that sufficient time is available for their development, three dimensional shallow-water maxima up to three times the 


\section{HURRICANE STORM SURGE CONSIDERED AS A RESONANCE PHENOMENON}

static water displacement may be considered to be possible in nature.

Hence, a shallow-water maximum of three times the static water displacement, combined with total reflection against the coast, could explain storm surges up to six times the static water displacement. Storm surges of this magnitude have frequently been observed (Harris, 1958).

The steepness of the shallow-water maxima is of the same order of magnitude as the steepness of tsunamis. Hence, they may be affected by the coast in such a way, that the elevation of water level at the coast may be considerably more than twice their height, as is shown by Kaplan (1955) and van Dorn (1959). Thus, the shallow-water maxima, combined with the affects of the coast could even explain storm-surges higher than six times the static water displacement.

\section{ACKNOWLEDGEMENTS}

This investigation was conducted by the author while a Fulbright Scholar at the Hydraulics Research Laboratory, University of California, Berkeley. The work was performed under sponsorship of the National Science Foundation, grant number 4630 .

The author wishes to express his appreciation to Prof. J. W. Johnson for facilitating this investigation and to Prof. R. L. Wiegel for suggesting the study.

\section{REFERENCES}

Abraham, G. Model study of water gravity waves generated by a moving circular low pressure area, Univ . of Calif., Inst . of Eng. Res., Tech. Rept. 99-5, 122 pp, May 1959.

Donn, W. L. The Great Lakes Surge of May 5, 1952; Journal of Geophysical Research, vol. 64, No. 2, pp 191-198, February 1959.

Ewing, M. F., F. Press, and W. L. Donn. An explanation of the Lake Michigan Surge of 26 June, 1954, Science, vol. 120, pp 684-686, October 1954.

Harris, D. Lee. Some problems involved in the study of storm surges: National Hurricane Research Project, Report 4, 1956.

Harris, D. Lee. Meteorological aspects of storm surge generation: Journal of the Hydraulic Division, Proceedings of the American Society of Civil Engineers, paper 1859, Hy 7, December 1958 . 


\section{COASTAL ENGINEERING}

Havelock, T. H. The effect of shallow water on wave resistance: Proceedings of the Royal Society of London, series A, vol. 100, 1922 .

Inui, T. On deformation, wave patterns and resonance phenomenon of water surface due to a moving disturbance: Proceedings of the Physico-Mathematical Society of Japan, series 3, vol.18, no. 2, February 1936 .

Kaplan, K. Generalized laboratory study of tsunami run-up: Technical Memorandum no. 60, Beach Erosion Board, January 1955.

Redfield, A. C. and A. R. Miller. Memorandum on water levels accompanying Atlantic Coast hurricanes: Woods Hole Oceanographic Institution, Reference no. 55-28, June 1955 (unpublished manuscript).

Redfield, A. C. and A. R. Miller. Water levels accompanying Atlantic Coast hurricanes: Meteorological monographs, vol. 2, no. 10, June 1957.

Snyder, C. M., R. L. Wiegel and K. J. Bermel, Laboratory facilities for studying water gravity wave phenomenon, Proc. Sixth Conf. on Coastal Engineering, Council on Wave Research, The Engineering Foundation, pp 231-251, 1958 .

Van Dorn, W. G. Local effects of impulsively generated waves, report no. II, Scripps Institution of Oceanography, August 1959.

Wiegel, R. L., C. M. Snyder, J. B. Williams. Water gravity waves generated by a moving low pressure area: Transactions of the American Geophysical Union, vol. 39, no. 2, April 1958. 